Revista Tecné, Episteme y Didaxis: TED. Año 2014, Número Extraordinario. ISSN Impreso: 0121-3814, ISSN web: 2323-0126

Memorias, Sexto Congreso Internacional sobre Formación de Profesores de Ciencias. 08 al 10 de octubre de 2014, Bogotá

\title{
Caracterización de los contenidos curriculares contextualizados para la enseñanza de la química
}

Piñeros, Yaneth' y Parga, Diana²

Categoría 2. Trabajo de investigación (en proceso)

\section{Resumen}

El presente escrito describe la problemática relacionada con la pertinencia de los contenidos curriculares para la enseñanza de la química en la educación básica y media en Colombia; estos se han destacado por su falta de relevancia cuando se enseñan al estudiante, por lo tanto, deberían enfocarse como un conocimiento importante para comprender el mundo, entre ellos el cotidiano. Por lo general, la enseñanza de la química utiliza currículos sustentados en una variedad de temáticas relacionadas con las ramas de esta ciencia pero que dejan de lado intereses y motivaciones de ellos, muy alejados de su contexto, por lo tanto, se hacen irrelevantes para el estudiante. Por lo anterior, se propone realizar una investigación que diseñe e implemente una nueva propuesta curricular para comprender lo que significa un currículo contextualizado y de interés para el estudiantado.

\section{Palabras clave}

Química contextualizada, Currículo, Contexto.

\section{Intenciones de la investigación}

El objetivo que se ha planteado para esta investigación es analizar el impacto que pueda tener una propuesta curricular para la enseñanza de la química que articule lo disciplinar con la enseñanza de una química contextualizada en el Plan de estudios del grado $10^{\circ}$ del Colegio Técnico Class IED, jornada tarde.

1 Estudiante de Maestría Docencia de la Química. Universidad Pedagógica Nacional.janepica2@hotmail.com

2 Profesora de la Universidad Pedagógica Nacional.dparga@pedagogica.edu.co 
Revista Tecné, Episteme y Didaxis: TED. Año 2014, Número Extraordinario. ISSN Impreso: 0121-3814, ISSN web: 2323-0126

Memorias, Sexto Congreso Internacional sobre Formación de Profesores de Ciencias. 08 al 10 de octubre de 2014, Bogotá

\section{Marco teórico}

Es innegable que la educación y los procesos de enseñanza han sido producto de las políticas gubernamentales que imperan en cada momento de la historia de nuestro país, como lo afirma Patiño (2014), la historia de la educación en Colombia es una sucesión de normas sobre el papel; buenas intenciones que sólo obedecen a los deseos de los legisladores de turno; políticas reformistas y sus correspondientes contrarreformas que anulaban, de tajo, los logros alcanzados; reivindicaciones salariales, protestas, imposiciones; recetarios traídos por misiones extranjeras, etc. que bien podría resumirse en varios intentos fallidos, los más, por inscribir al país en la modernidad.

Sumado a esto, la enseñanza de la química en la educación media en Colombia es una disciplina básica en el currículo que se ha caracterizado por estar lleno de contenidos; como producto un aprendizaje sin sentido, ni una aplicabilidad en contextos reales. Para que la enseñanza de las ciencias y en especial de la química sea valedera y relevante, se han realizado investigaciones que implican contextualizar los contenidos escolares, en busca de mostrar al estudiante la importancia de la química desde un punto sociocultural y ambiental. Que se muestre como algo cercano a su mundo y responda a sus necesidades.

Dentro de los objetivos fundamentales que se han considerado en la enseñanza de las ciencias en Colombia, está el de presentarla como algo útil y no tan alejada del contexto del estudiante, frente a los cambios presentados en la sociedad y a la necesidad de implementar una educación acorde con las necesidades sociales, los entes encargados de los procesos educativos como el Ministerio de Educación Nacional que busca mejorar la calidad educativa e involucrar a los estudiantes en unos procesos educativos también de calidad y a partir de los resultados de diversas evaluaciones, desarrolló una propuesta de estándares curriculares, inicialmente para las áreas de matemáticas, lengua castellana, ciencias naturales y educación ambiental que precisan, para cada área del conocimiento y grado, los desempeños que todos los estudiantes del país deben alcanzar (MEN, 2004).

Así, los estándares son criterios claros y públicos que permiten conocer lo que deben aprender nuestros niños, niñas y jóvenes; establecen el punto de referencia en relación con la capacidad de saber y saber hacer, en cada una de las áreas y niveles; se definen unas metas de la formación en ciencias en la educación básica y media tales como: 
Revista Tecné, Episteme y Didaxis: TED. Año 2014, Número Extraordinario. ISSN Impreso: 0121-3814, ISSN web: 2323-0126

Memorias, Sexto Congreso Internacional sobre Formación de Profesores de Ciencias. 08 al 10 de octubre de 2014, Bogotá

- Favorecer el desarrollo del pensamiento científico

- Desarrollar la capacidad de seguir aprendiendo.

- Desarrollar la capacidad de valorar críticamente la ciencia.

- Aportar a la formación de hombres y mujeres miembros activos de una sociedad

Con estas metas, se buscaba brindar bases a los estudiantes para que se acercaran a la actividad científica y alcancen niveles de comprensión más complejos, reconociendo así que los conceptos abordados en las disciplinas naturales permitiesen comprender situaciones y relaciones propias de su contexto. La organización de mallas curriculares de cada institución debería estar orientada por dicho documento de tal forma que lograran implementar en el estudiante el desarrollo de un pensamiento científico y crítico, de unas habilidades y actitudes científicas que le permitan dar explicación a fenómenos enmarcados en la ciencia (MEN, 2004, pág. 109)

En la búsqueda de fortalecer estos procesos educativos y alcanzar unos niveles de calidad óptimos, en el plan sectorial 2008-2012 "Educación de Calidad para una Bogotá Positiva" se implementa la Reorganización Curricular por Ciclos, como una estrategia para alcanzar la excelencia. Asimismo, hoy se plantean aprendizajes esenciales, que un estudiante deben alcanzar durante su escolaridad para desenvolverse en su cotidianidad, resolver de manera ética situaciones que se le presenten en su vida, y esto requiere que la escuela contextualice sus prácticas (SED, 2008, pág. 98), pues como lo proponen Mora y Parga (2010, pág: 86) "El currículum ha de conformar creencias, actitudes y valores que, fundamentalmente, desarrollen un interés crítico por la actividad científica. Actitudes y valores que le permitan valorar el papel que la ciencia juega y ha jugado en nuestras vidas y preparen así el camino para que, en un futuro próximo, estos estudiantes puedan participar colectivamente en la solución de los problemas con los que se enfrenta la sociedad de la que forman parte".

En el ámbito internacional también se han generado propuestas y proyectos de investigación tendientes a mostrar una química más atractiva y más aplicable para el estudiante en busca de ser más motivadora dentro del aula de clase. En los años setenta y ochenta se elaboraron proyectos como: los proyectos estadounidenses Chemical Bond Approach (CBA), y CHEM (Chemistry- An experimental Science), los proyectos ingleses de la fundación Nuffield: Curso Modelo de Química (1969-1973), para la educación secundaria obligatoria, y Química Avanzada Nuffield (1974-76), para el bachillerato (Mora y Parga, 2010). 
Revista Tecné, Episteme y Didaxis: TED. Año 2014, Número Extraordinario. ISSN Impreso: 0121-3814, ISSN web: 2323-0126

Memorias, Sexto Congreso Internacional sobre Formación de Profesores de Ciencias. 08 al 10 de octubre de 2014, Bogotá

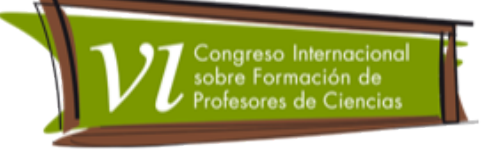

En España el proyecto Química Faraday (Grup Recerca-Faraday, 1988), más recientes como el proyecto estadounidense QuimCom (Química en la Comunidad) $O$ el proyecto inglés Salters Advanced Chemistry, que ha sido adaptado en diferentes países (Caamaño, 2006).

La búsqueda de estrategias que aproximen verdaderamente al estudiante a la comprensión de lo que implica la función y estudio de la química, requiere contextualizar un currículo, enfocarlo en unos contenidos que estén inmersos en lo que es motivador para el estudiante, Pilot y Bulte (2006) citado por Jiménez-Liso y De Manuel(2009), proponen dos principios para aumentar la importancia de un contenido químico en las aulas de ciencia: por un lado, la elección de los contextos como punto de partida en el diseño de unidades didácticas o del currículo y, por otro lado, para la selección del contenido y/o actividades, tener siempre presente lo que sería necesario para comprender ese contenido, actividad o contexto.

Por todo esto es necesario y urgente replantear lo que se enseña, como se enseña y para qué se enseña, es necesario realizar el diseño de un currículo que presente contenidos y temáticas que despierten un verdadero interés en el estudiante. Al respecto Izquierdo (2004) afirma que es el momento de aportar nuevas ideas para culminar los cambios que se anuncian y conseguir superar el reto que tenemos planteado ahora los profesores de química: hacer que la química sea comprensible para el gran público y ocupe su lugar como ciencia básica pero al servicio de otras nuevas que están emergiendo, sin que por ello se convierta en una banalidad.

Surge la necesidad de abarcar unos contenidos científicos de forma contextualizada, que permitan al estudiante concientizarse de la utilidad y aplicabilidad de dichos contenidos, como también las implicaciones sociales de la ciencia. Cuando se habla de una química contextualizada se hace referencia a como se puede utilizar el contexto para desarrollar unos conceptos que la relacionen con la cotidianidad actual y futura; teniendo en cuenta que esta forma de abordar la enseñanza genera más interés y motivación en el estudiante, y aumenta el interés por continuar estudios centrados en la ciencia (Caamaño, 2006).

Es posible que enfoques como el de cuestiones sociocientíficas (CSC) ${ }^{3}$ O

${ }^{3}$ Las cuestiones sociocientíficas abarcan discusiones, controversias o temas de interés público 
Revista Tecné, Episteme y Didaxis: TED. Año 2014, Número Extraordinario. ISSN Impreso: 0121-3814, ISSN web: 2323-0126

Memorias, Sexto Congreso Internacional sobre Formación de Profesores de Ciencias. 08 al 10 de octubre de 2014, Bogotá

socioambientales (CSA), sean pertinentes para estos objetivos, así como para la formación ciudadana de los estudiantes con los cuales puedan comprender la ciencia como una actividad humana que presenta múltiples controversias e incertidumbres en su constitución y por tanto, se requiera de un análisis crítico de sus alcances e impactos (Martínez y Parga, 2013a).

De otro lado, se debe enfatizar en la importancia que tiene la formación del docente, ya que las dificultades generadas dentro del aula en los procesos de aprendizaje no solo son producto de un currículo, con deficiencias en su diseño, como plantea Padilla (2012), de nada sirve tener unos planes y programas bien estructurados, con un enfoque constructivista que permiten el desarrollo de habilidades de pensamiento, valores y actitudes, si los docentes no cambian sus prácticas pedagógicas.

\section{Metodología}

El marco metodológico en el cual se enmarca la presente propuesta es de tipo cualitativo ya que se orienta y describen los fenómenos sociales y por consiguiente los educativos y se interesa por el estudio de los significados y acciones humanas desde la perspectiva de los mismos agentes sociales (Sandin, 2003). La investigación se fundamenta en el marco teórico-práctico de la investigación-acción (IA) que está interesada en los problemas prácticos de las aulas y en encontrar soluciones a los mismos. Implica el desarrollo profesional del profesorado, y la idea de ellos como investigadores y promotores del cambio en las escuelas (Elliot, 2005)

Los participantes de la investigación son los estudiantes de grado decimo $10^{\circ} \mathrm{del}$ Colegio Técnico Class, jornada mañana y tarde con la participación de dos docentes de química. La sede A esta integrada por los estudiantes que conforman los grados de $6^{\circ}$ a $11^{\circ}$. Cuenta con un programa de Educación Media fortalecida con la Corporación Universitaria Minuto De Dios.

La información se recolectará mediante entrevistas, encuestas, observación de clase, discusión y análisis con pares académicos. Las fases en que se desarrollará la propuesta se describen a continuación:

directamente relacionados con investigaciones tecnocientíficas de gran impacto en la sociedad. Estas cuestiones son frecuentemente divulgadas en los medios de comunicación de forma limitada lo que genera diferentes percepciones públicas sobre la tecnociencia (Martínez y Parga, 2013b). 
Revista Tecné, Episteme y Didaxis: TED. Año 2014, Número Extraordinario. ISSN Impreso: 0121-3814, ISSN web: 2323-0126

Memorias, Sexto Congreso Internacional sobre Formación de Profesores de Ciencias. 08 al 10 de octubre de 2014, Bogotá

- Fase de diagnóstico: se realizará una caracterización del currículo del Colegio Técnico Class para determinar el cambio que se desea instaurar en el diseño curricular.

- Fase de Diseño: Diseño de un currículo (meso currículo y microcurrículo) fundamentado en contenidos contextualizados.

- Fase de Implementación y evaluación: aplicar una unidad didáctica desde un enfoque contextualizado y para los estudiantes del grado décimo de Colegio Técnico Class. Este enfoque se basará en el de cuestiones sociocientíficas o socioambientales.

\section{Resultados esperados}

En el proceso de construcción de la investigación se ha podido evidenciar a través de la revisión bibliográfica que los trabajos relacionados con la enseñanza de una química contextualizada generan más motivación al estudiante, facilitando su proceso de aprendizaje ya que le permite relacionar su cotidianidad con los contenidos desarrollados en el aula.

Con la presente investigación se espera obtener los siguientes resultados:

- Estructurar una nueva propuesta de contenido micro curricular para la enseñanza de una química contextualizada basada en el enfoque de las cuestiones sociocientíficas o socioambientales.

- Analizar el impacto que pueda tener la propuesta en los estudiantes y docentes de química del Colegio Técnico Class.

\section{Conclusiones}

Con el diseño curricular propuesto, se espera incidir de manera favorable en el cambio actitudinal de los estudiantes frente a la comprensión de la química, y frente a la imagen que de ella tienen. Asimismo, se espera aportar con indicadores para la formación del profesorado de química respecto a nuevas perspectivas en el diseño curricular pertinentes para las necesidades sociales actuales. 
Revista Tecné, Episteme y Didaxis: TED. Año 2014, Número Extraordinario. ISSN Impreso: 0121-3814, ISSN web: 2323-0126

Memorias, Sexto Congreso Internacional sobre Formación de Profesores de Ciencias. 08 al 10 de octubre de 2014, Bogotá

\section{Referencias Bibliográficas}

Amparo Vilches, C. F. (1999). Ciencia Tecnología Sociedad. Obtenido de http://www.oei.es/salactsi/ctseducacion.htm

Caamaño, A. (2006). Retos del currículum de química en la educación secundaria. la selección y contextualización de los contenidos de química en los currículos de Inglaterra, Portuga, Francia y España. Ponencia.

Elliot, J. (2005). La investigación-acción en educación. Madrid: Morata. Martínez, L. y Parga, D. (2013a). La emergencia de las cuestiones sociocientíficas en el enfoque CTSA. En Gondola, 8(1), pág. 23-35.

Martínez, L. y Parga, D. (2013b). Discurso ético y ambiental sobre cuestiones sociocientíficas: aportes para la formación del profesorado. Bogotá: (c) Universidad Pedagógica Nacional.

MEN. (2004). Estandares básicos de competencias en Ciencias sociale y Ciencias naturales. Bogotá.

Millan, C.P. (2014). marthahistoriayfilosofíadelaeducación. Obtenido de http://marthahistoriayfilosofiadelaeducacion.wikispaces.com/

Mora, W y Parga, D. (2010). La imagen pública de la química y su relación con la generación de actitudes hacia la química y su aprendizaje. Tecné, Episteme y Didaxis: TED. 27, pág. 67-93.

Piehrahita, S. (2009). Rafael de la Zerda y la Química en Colombia en el siglo XIX. Boletín de Historia y Antiguedades, 96 (846).

Ramírez, I. B. (Diciembre de 2002). A proposito de un texto para la enseñanza de la química editado a principios del siglo XX en Colombia. Rev. Acad. Colomb., XXVI(101). 
Revista Tecné, Episteme y Didaxis: TED. Año 2014, Número Extraordinario. ISSN Impreso: 0121-3814, ISSN web: 2323-0126

Memorias, Sexto Congreso Internacional sobre Formación de Profesores de Ciencias. 08 al 10 de octubre de 2014, Bogotá

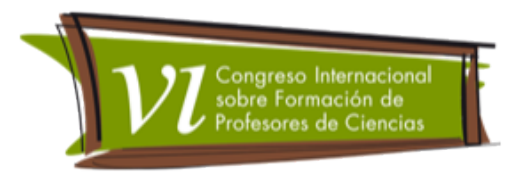

Sandin, M. (2003). Obtenido de

http://www.postgrado.unesr.edu.ve/acontece/es/todosnumeros/num09/02_ 05/capitulo_7_de_sandin.pdf

SED. (2008). Reorganización Curricular por Ciclos. Bogotá: Imprenta Nacional de Colombia. 